\title{
Efeito de bactérias diazotróficas nos componentes de produção de cana-de-açúcar infectadas pelo raquitismo das soqueiras
}

\section{Effect of diazotrophic bacteria in the production components of sugarcane infected with ratoon stunting disease}

\author{
Silvana Regina de Souza ${ }^{1 *}$, Edelclaiton Daros ${ }^{1}$, Reginaldo Batista Fragoso ${ }^{1}$ e Lucimeris \\ Ruaro ${ }^{1}$
}

${ }^{1}$ Universidade Federal do Paraná, Setor de Ciências Agrárias, Departamento de Fitotecnia e Fitossanitarismo, Rua dos Funcionários no 1540, Cabral. CEP: 80035-050, Curitiba PR.

\begin{abstract}
The aim of this study was to evaluate the effects of diazotrophic bacteria in the yield components of sugarcane infected with the ratoon stunting disease caused by Leifsonia xyli subsp. xyli. The test was conducted at the Experimental Station Paranavaí, PR, 2010. The treatments consisted of genotype SP77-5181 inoculated with: 1. Azospirillum brasiliense strain AbV5 + Leifsonia xyli subsp. xyli; 2. Herbaspirillum seropedicae strain SMR1 + Leifsonia xyli subsp. xyli; 3. Herbaspirillum seropedicae strain HCC103 + Leifsonia xyli subsp. xyli; 4. Leifsonia xyli subsp. xyli; 5. All bacteria (Azospirillum brasiliense + Herbaspirillum seropedicae + Leifsonia xyli subsp. xyli), 6. No inoculated treatment. Evaluations were made of: POL, tons of POL per hectare, fiber content, weight of a culm, number of stems per meter, height, stalk diameter and tons of cane per hectare for each treatment. The detection of the pathogen was analyzed by Dot blot. The design was a randomized block design with three replications. It was found that Herbaspirillumn seropedicae SMRI strain, showed potential as biological control of colonization Leifsonia xyli subsp. xyli, based on evidence such as increasing the mass of stalks. Apparently the bacteria Azospirillum brasiliense strain: AbV5 caused no detectable effects on yield components evaluated.

Key-words: Saccharum spp., Herbaspirillum seropedicae, Azospirillum brasilense, endophytic bacteria, biocontrol
\end{abstract}

\section{INTRODUÇÃO}

Dentre os patógenos mais importantes que incidem na cultura da cana-de-açúcar está a bactéria Leifsonia xyli subsp. xyli (Young et al., 2006), que corresponde à bactéria causadora do raquitismo-da-soqueira (RSD - "Ratoon Stunting Disease"). Classificada no grupo corineforme, é gran-positiva, aeróbica, pleomorfica e fastidiosa, têm forma reta ou levemente curva e ocasionalmente inchada na ponta ou no meio, são bastonetes pleomórficas de $0,25-0,25 \mu \mathrm{m}$ por 1-4 $\mu \mathrm{m}$ (Teakle et al., 1978).

As estratégias de controle do RSD visam evitar a entrada do inóculo inicial $\left(\mathrm{X}_{0}\right)$ nas áreas de produção. A principal medida é por meio de resistência varietal e o emprego do tratamento térmico de toletes ou minitoletes durante $50,5^{\circ} \mathrm{C}$ por $2 \mathrm{~h}$ ou $52{ }^{\circ} \mathrm{C}$ por $30 \mathrm{~min}$. Esta prática possui algumas limitações que desestimulam os produtores a empregá-la, tais como: custos do equipamento e da mão-de-obra; perdas de gemas ocasionando falhas na germinação, manutenção de viveiros primários com sistemas adequados de irrigação e, principalmente, o reduzido efeito residual do tratamento que permite uma nova reinfestação da doença, já na primeira colheita (Damann e Olliver, 1991). Outra forma de controle é por meio da produção de mudas sadias por cultura de meristema (Lee, 1988), mas o plantio de mudas micropropagadas é relativamente baixo, devido ao custo elevado das mudas e necessidade de manutenção de viveiros primários. Um método alternativo para controle do RSD é o controle biológico, por meio de bactérias endofíticas, as

Author for correspondence: souuza@hotmail.com 
quais são capazes de colonizar os tecidos da planta hospedeira, competindo pelos mesmos sítios de colonização com o patógeno. Podem também induzir resistência ou produzir bacteriocinas danosas ao patógeno, possibilitando estender os efeitos benéficos do tratamento térmico e que variedades com baixa resistência a doença, mas com grande potencial produtivo, sejam aproveitadas pelos programas de melhoramento e produtores (Olivares et al., 2000).

$\mathrm{Na}$ cultura da cana-de-açúcar, já foram descritas várias espécies de bactérias diazotróficas, essas bactérias são capazes de fixar nitrogênio do ar e algumas colonizam o interior dos vasos do xilema da planta, podendo ocupar provavelmente os mesmos sítios de colonização que bactérias fitopatogênicas, como é o caso de $L$. xyli subsp. xyli (Olivares et al., 2000). Avaliando o potencial de bactérias diazotróficas endofíticas no controle do raquitismo da cana-de-açúcar, Carneiro Jr. (2001) utilizando tratamentos combinados de endofíticas/patógeno, encontrou resultados positivos, ocorrendo uma indução de tolerância ao raquitismo e melhoria no rendimento agronômico.

O objetivo deste trabalho foi avaliar o efeito de bactérias diazotróficas nos componentes de produção de cana-de-açúcar infectadas pelo raquitismo das soqueiras causado por Leifsonia xyli subsp. xyli.

\section{MATERIAL E MÉTODOS}

O experimento foi conduzido a campo, nos anos agrícolas de 2009/2010 na Estação Experimental de Paranavaí, do Setor de Ciências Agrárias (SCA), da UFPR localizada no município de Paranavaí, PR, região Noroeste do Estado, entre as coordenadas $23^{\circ} 50^{\prime} 05$ de latitude Sul e $52^{\circ} 26^{\prime}$ de longitude Oeste, com altitude média de $470 \mathrm{~m}$.

O local apresenta clima tipo Cfa, conforme classificação de Köppen, subtropical, com temperatura média no mês mais frio inferior a 18 ${ }^{\circ} \mathrm{C}$ (mesotérmico) e temperatura média no mês mais quente acima de $22{ }^{\circ} \mathrm{C}$, com verões quentes, geadas pouco freqüentes e tendência de concentração das chuvas nos meses de verão, contudo sem estação seca definida e precipitação média anual de 1.300 a 1.400 mm (IAPAR, 1994).

$\mathrm{O}$ experimento foi instalado em solo tipo Latossolo Vermelho Distrófico (LVd-1) com relevo suave ondulado. São solos muito profundos, formados a partir de materiais derivados de arenitos, com seqüência de horizontes A, B, C pouco diferenciados, coloração vermelha escura, porosos, muito friáveis, fortemente drenados, baixa fertilidade natural, ácidos, de baixo a médio teor de alumínio trocável e saturação de bases baixa (EMBRAPA, 1999).

Os isolados bacterianos endofíticos foram cedidos pelo Núcleo de Fixação de Nitrogênio do Departamento de Bioquímica e Biologia Molecular da UFPR. Para o cultivo foi utilizado meio NFbHP semi-sólido, obtido misturando-se meio sólido e líquido na proporção $1 / 9$ no momento do uso (Pedrosa e Yates, 1984).

Como material propagativo, foram utilizados toletes da variedade SP77-5181, tratados termicamente antes do plantio ( $1^{\circ}$ corte), plantados em bandejas com substrato à base de vermiculita em abril de 2009 e mantidos em viveiro-telado (sombrite 50\%). Decorridos 50 dias as plântulas foram inoculadas com as bactérias: Azospirillum brasilense (estirpe AbV5) e Herbaspirillum seropedicae (estirpes SmR1 e HCC 103), com o uso de seringa contendo $0,5 \mathrm{ml}$ do meio com o inóculo previamente padronizado quanto ao número mais provável (NMP) de colônias (concentração de $3 \times 10^{10} \mathrm{ufc} / \mathrm{mL}$ ), aplicado no colo das plântulas.

A bactéria Leifsonia xyli. subsp. xyli (causadora do RSD) foi inoculada aos 140 dias do transplantio, por meio da poda das folhas basais com tesoura pré-imersa em seiva contaminada da variedade SP77-5181, altamente suscetível e comprovadamente infectada por Leifsonia xyli subsp. xyli, pelo teste sorológico de Dot Blot (Carneiro Jr., 2001).

Uma semana após a inoculação as plântulas foram transplantadas para o campo. $\mathrm{O}$ plantio foi realizado em sulcos de 5 metros de comprimento, 1,40 metros entre sulcos com profundidade de 20 a $25 \mathrm{~cm}$ e o espaçamento entre covas foi de 0,5 metro. No preparo do solo, foram realizadas duas gradagens, sendo a primeira realizada com grade aradora e a segunda, com grade niveladora. Em seguida foi feito o sulcamento para o plantio das plântulas. A adubação utilizada foi $20 \mathrm{~kg} \mathrm{ha}^{-1} \mathrm{de}$ $\mathrm{N}, 100 \mathrm{~kg} \mathrm{ha}^{-1}$ de $\mathrm{K}_{2} \mathrm{O}$ e $100 \mathrm{~kg} \mathrm{ha}^{-1}$ de $\mathrm{P}_{2} \mathrm{O}_{5}$.

Os tratamentos foram constituídos de plantas da variedade SP77-5181 inoculadas com: 1 . Azospirillum brasilense estirpe AbV5 + Leifsonia xyli subsp. xyli, 2. Herbaspirillum seropedicae estirpe SmR1 + Leifsonia xyli subsp. xyli, 3 . Herbaspirillum seropedicae estirpe $\mathrm{HCC} 103+$ Leifsonia xyli subsp. xyli, 4. Leifsonia xyli subsp. xyli, 5. Todas bactérias: Azospirillum brasilense AbV5 + Herbaspirillum seropedicae SmR1 + 
Herbaspirillum seropedicae HCC103 + Leifsonia xyli subsp. xyli e 6. Testemunha sem inoculação (TE).

Os componentes de produção avaliados foram: POL (pol cana) através da fórmula: Pol $=\left(a / c+1-0,01 \times F i b_{d}\right)$, em que $a=1000 \mathrm{~g}$ $\mathrm{H}_{2} 0, c=500 \mathrm{~g}$ de cana, $s$ refere-se ao pol no extrato do digestor, onde, $s=L_{d} \times(0,2605-0,001 \times b)$ e $L_{d}$ corresponde à leitura sacarimétrica do extrato e $b$ ao brix $\%$ extrato do digestor, $\mathrm{Fib}_{d}$ ao teor de fibra da cana obtida pelo método do digestor, toneladas de POL por hectare (TPH) através da fórmula: $\mathrm{TPH}=$ (TCH x POL) / 100, teor de fibra (realizadas no Laboratório de análises tecnológicas da Usina Alto Alegre localizada no município de Colorado, PR), massa de 1 colmo (M1C) calculada em função da média de três pesagens de dez (10) colmos por parcela $(\mathrm{kg})$, obtido por $M 10 C / 10$, número de colmos por metro (NCM), estatura, diâmetro de colmos e toneladas de cana por hectare $(\mathrm{TCH})$ conforme a fórmula a seguir: $\mathrm{TCH}=(\mathrm{M} 1 \mathrm{C} \mathrm{x}$ NCM) x 7,148/1,40.

O delineamento utilizado foi de blocos ao acaso, com três repetições e os dados resultantes foram submetidos à análise de variância $(\mathrm{p} \leq 0,05)$ utilizando-se o Software SISVAR 5.3 (Ferreira, 2000) e as médias comparadas pelo teste de Scott knott a $5 \%$.

O ensaio foi instalado em junho de 2009 e as amostras para análise de detecção da bactéria causadora do raquitismo foram colhidas das plantas aos 11 meses de idade em maio de 2010. No momento da coleta das amostras os colmos foram coletados e limpos com pano úmido e devidamente identificados, sendo realizado um corte em bisel na parte superior e um corte transversal na parte inferior, para facilitar o encaixe do colmo e o escorrimento do fluido vascular para o microtubo, logo após, foi imediatamente iniciada a extração de aproximadamente $1000 \mu \mathrm{L}$ de fluido vascular entre o segundo e terceiro entrenó da base para o ápice com auxílio de um compressor de baixa pressão, adaptado com uma teteira de borracha (tipo ordenhadeira) na extremidade da mangueira a fim de facilitar a extração. Foram coletadas 10 amostras para cada tratamento e repetição, totalizando 180 amostras que foram acondicionadas em microtubos de $1500 \mu \mathrm{L}$, contendo duas gotas de solução estabilizadora de digluconato de clorexidina a $0,02 \%$, acondicionados em isopor com gelo e o conteúdo foi levado para o Laboratório de Fitopatologia da Universidade Federal do Paraná.

Para a análise de detecção do patógeno, foi utilizado anti-soro policlonal específico contra Leifsonia xyli subsp. xyli produzido por Carneiro Jr. et al. (2006), segundo protocolo de (Harisson e Davis, 1988), modificado por Carneiro Jr. et al. (2006). A coleta de amostras para o isolamento e quantificação da população das bactérias endofíticas foi realizada em junho de 2010. Foram coletadas raízes com solo na profundidade de aproximadamente 20 centímetros de comprimento, da raiz para o colmo de cada tratamento. Este material foi colocado em sacos plásticos, acondicionados em caixas de isopor com gelo e encaminhadas para o Laboratório da Universidade Federal do Paraná (UFPR), onde foram processadas segundo (Döbereiner et al., 1995).

\section{RESULTADOS E DISCUSSÃO}

$\mathrm{Na}$ análise dos componentes de produção (Tabela 1), foi verificada diferença significativa somente para diâmetro (DC) e massa colmos (M1C). O tratamento inoculado apenas com Leifsonia xyli subsp. xyli apresentou menor diâmetro, $\operatorname{com} 2 \mathrm{~cm}$, diferindo-se dos demais tratamentos. Os tratamentos Leifsonia xyli subsp. xyli e Azospirillum brasilense estirpe AbV5 + Leifsonia xyli subsp. xyli apresentaram os menores valores de massa de colmos com $0,81 \mathrm{~kg}$ e $0,72 \mathrm{~kg}$ respectivamente. 
Tabela 1. Componentes de produção de toneladas de cana por hectare $(\mathrm{TCH})$, toneladas de POL por hectare (TPH), POL, teor de fibra (\%), diâmetro de colmos (DC), massa de um colmo (M1C), número de colmos por metro (NCM) e estatura de colmos (EC) de plantas de cana-de-açúcar da variedade SP775181 pré inoculadas com bactérias endofíticas e pós inoculadas com Leifsonia xyli subsp. xyli. Município de Paranavaí/PR, 2010.

\begin{tabular}{|c|c|c|c|c|c|c|c|c|}
\hline Tratamentos & $\mathbf{T C H}^{\mathrm{ns}}$ & $\mathbf{T P H}^{\mathrm{ns}}$ & Pol $^{\text {ns }}$ & $\begin{array}{l}\text { Teor de } \\
\text { fibra }(\%)^{\text {ns }}\end{array}$ & $\mathrm{DC}(\mathrm{cm})$ & M1C (kg) & $\mathrm{NCM}^{\mathrm{ns}}$ & $\begin{array}{l}\text { EC } \\
(\mathbf{m})^{\mathrm{ns}}\end{array}$ \\
\hline \multicolumn{9}{|c|}{ Hs HCC $103+$} \\
\hline$L x x$ & 84,19 & 11,95 & 14,20 & 12,96 & $2,50 \mathrm{~b}$ & $0,86 \mathrm{~b}$ & 13,60 & 1,80 \\
\hline$H s \mathrm{SmR} 1+L x x$ & 89,64 & 12,77 & 14,21 & 12,75 & $2,30 \mathrm{~b}$ & $0,92 \mathrm{~b}$ & 13,63 & 1,91 \\
\hline$A b \mathrm{AbV} 5+L x x$ & 74,79 & 10,46 & 13,94 & 13,01 & $2,23 \mathrm{~b}$ & $0,72 \mathrm{a}$ & 13,40 & 1,81 \\
\hline$L x x$ & 80,90 & 11,32 & 13,99 & 13,30 & $2,00 \mathrm{a}$ & $0,81 \mathrm{a}$ & 13,93 & 1,88 \\
\hline Todas bactérias & 89,71 & 13,05 & 14,53 & 12,82 & $2,30 \mathrm{~b}$ & $0,93 \mathrm{~b}$ & 13,40 & 1,96 \\
\hline Testemunha & 89,29 & 12,57 & 14,05 & 12,93 & $2,36 \mathrm{~b}$ & $0,91 \mathrm{~b}$ & 13,73 & 1,91 \\
\hline C.V.\% & 6,95 & 11,06 & 5,90 & 6,99 & 4,15 & 6,87 & 4,77 & 9,73 \\
\hline
\end{tabular}

ns - não significativo pelo teste Scott knott $\mathrm{P} \leq 0,05$; Hs HCC 103 - Herbaspirillumn seropedicae estirpe HCC 103; Hs SmR1 - Herbaspirillumn seropedicae estirpe SmR1; Ab AbV5 - Azospirillum brasilense estirpe AbV5; Lxx Leifsonia xyli subsp. Xyli

O menor diâmetro de colmos observado nas plantas inoculadas somente com Leifsonia xyli subsp. xyli possivelmente expressa o efeito negativo na característica associada à massa de colmos, a qual também foi menor nestas plantas. Estes resultados confirmam os sintomas característicos da presença de Leifsonia xyli subsp. $x y l i$, que são colmos mais finos e internódios mais curtos (Tokeshi, 1997), porém não observou-se diferença significativa entre os tratamentos para estatura de colmos.

Os melhores resultados para massa de colmos foram apresentados pelos tratamentos com Herbaspirillum seropedicae estirpe SmR1+ Leifsonia xyli subsp. xyli, com Herbaspirillum seropedicae estirpe HCC 103+ Leifsonia xyli subsp. $x y l i$, na inoculação conjunta de todas as bactérias (inóculo mixto) e na testemunha. Também foram nestes tratamentos que Herbaspirillum seropedicae SmR1 se apresentou com números populacionais altos comparados aos demais endófitos (Tabela 2) .

$\mathrm{O}$ uso de todas as bactérias proporcionou melhor desempenho das plantas quanto aos componentes de produção observados na Tabela 1, poderia ser atribuído à ação conjunta das bactérias, pela competição por espaço, oxigênio e nutrientes com o patógeno. Carneiro Jr. (2001) também encontrou resposta positiva com a associação de bactérias endofíticas e Leifsonia xyli subsp. xyli (Gluconacetobacter diazotrophicus, Herbaspirillum seropedicae e Herbaspirillum rubrisubalbicans), que foi positiva para a maioria dos componentes avaliados.

$\mathrm{Na}$ avaliação para a detecção de Leifsonia xyli subsp. xyli, pode-se constatar que os tratamentos com uso de Herbaspirillum seropedicae SmR1 + Leifsonia xyli subsp. xyli e a testemunha apresentaram maior incidência de Leifsonia xyli subsp. xyli com $25 \%$ das amostras soropositivos, seguidos pelo tratamento inoculado com todas as bactérias com $20 \%$ de incidência. Os tratamentos com Herbaspirillum seropedicae $\mathrm{HCC} 103+$ Leifsonia xyli subsp. xyli e Azospirillum brasiliense AbV5 + Leifsonia xyli subsp. xyli apresentaram as menores incidências, com 10\% das amostras soropositivos (Tabela 2).

$\mathrm{Na}$ quantificação das bactérias diazotróficas endofíticas verificou-se que Herbaspirillum seropedicae estirpe $\mathrm{SmR} 1$ apresentou números populacionais altos no tratamento em que foi inoculado em associação com Leifsonia xyli subsp. xyli, em comparação aos demais tratamentos. Em segundo lugar, está Herbaspirillum seropedicae HCC 103 com números populacionais também elevados no tratamento em foi inoculado em associação com Leifsonia xyli subsp. xyli, em comparação aos demais tratamentos. Azospirillum brasilense AbV5 se apresentou com valores populacionais baixos no tratamento em que foi inoculado em associação com Leifsonia xyli subsp. xyli e não detectado nos demais tratamentos, nem mesmo naquele onde todas as bactérias foram inoculadas (Tabela 2). 
Tabela 2. Incidência de Leifsonia xyli subsp. xyli (\%) e densidade de talos (DTB) bacterianos $\left(\mathrm{n}^{\circ}\right.$ células gramas de massa fresca ${ }^{-1}$ de raiz) das bactérias endofíticas, estimada pelo número mais provável (NMP), em meio semi-seletivo, avaliadas em plantas de cana-de-açúcar da variedade SP77-5181 pré inoculadas com bactérias endofíticas e pós inoculadas com Leifsonia xyli subsp. xyli. Município de Paranavaí/PR.

\begin{tabular}{|c|c|c|c|}
\hline \multirow{2}{*}{ Tratamentos } & \multirow{2}{*}{$\begin{array}{c}\text { Incidência } \\
L x x(\%)\end{array}$} & \multicolumn{2}{|c|}{ DT $\left(\mathrm{N}^{\circ}\right.$ células.g raiz $\left.{ }^{-1}\right)$} \\
\hline & & JNFb & NFb \\
\hline Herbaspirillum seropedicae HCC $103+$ Lxx & 10 & $4,5 \times 10^{3}$ & $\mathrm{nd}^{1}$ \\
\hline Herbaspirillum seropedicae $\mathrm{SmR} 1+L x x$ & 25 & $6 \times 10^{5}$ & $\mathrm{nd}^{1}$ \\
\hline Azospirillum brasilense AbV5 + Lxx & 10 & nd & $1,5 \times 10^{6}$ \\
\hline Todas as bactérias & 20 & $1,5 \times 10^{3}$ & $n d^{1}$ \\
\hline Testemunha & 25 & $\mathrm{nd}^{1}$ & $\mathrm{nd}^{1}$ \\
\hline
\end{tabular}

Nota: Lxx: Leifsonia xyli subsp. xyli; nd: não detectada na diluição superior a $10^{-4}$; nd ${ }^{1}$ não detectada na diluição superior a $10^{-2}$; JNFb meio seletivo para quantificação do NMP de Herbaspirillum; NFb meio seletivo para quantificação do NMP de Azospirillum brasilense

Era esperado que a inoculação com Azospirillum brasilense apresentasse efeito positivo na produção. Segundo Okon e Vanderleyden (1997) baseando-se em dados acumulados durante 22 anos de pesquisa com experimentos de inoculação a campo, concluíram que o gênero Azospirillum spp. promove ganhos em rendimento em importantes culturas nas mais variadas condições de clima e solo. Ao contrario do esperado, a inoculação com $A$. brasilense estirpe AbV5 + Leifsonia xyli subsp. xyli apresentou resultado negativo, diminuindo a produção e o diâmetro médio dos colmos. Esperava-se que A. brasilense colonizasse os vasos do xilema durante todo o ciclo da cultura da cana-de-açúcar e tivesse um efeito na redução da colonização de Leifsonia xyli subsp. xyli e conforme pode ser observado na Tabela 2, seus níveis populacionais foram muito baixos e não detectados para a maioria dos tratamentos. Entretanto, a dinâmica populacional das bactérias endofíticas e do patógeno são diferentes, enquanto o patógeno aumenta a população com a maturação e há uma tendência natural das bactérias endofíticas diminuírem (Costa e Ruschel, 1981).

Resultados semelhantes foram obtidos por Lopes et al. (2008) inoculando $H$. seropedicea na cultura do milho safrinha, não encontraram diferença significativa entre os tratamentos, porém, verificaram que as plantas inoculadas apresentaram produção de 444 (híbrido BRS 1030) e 540 (BR 106) $\mathrm{kg}$ a mais por hectare quando comparadas às plantas não inoculadas, o mesmo autor pode observar que a resposta do milho híbrido BRS 1030 na safra seguiu o caminho inverso, resultando em prejuízo à produtividade, esse fato demonstra que o resultado da inoculação com endofíticas pode ser dependente do genótipo da cultura estudada, assim também ocorreu em experimento com variedades de pepino, onde Liu et al. (1995) testando rizobactérias ( $P$. putida e Serratia marcescens) na indução de resistência em quatro variedades de pepino, sendo três suscetíveis e um resistente encontraram que $P$. putida induziu resistência nas três cultivares suscetíveis, mas $S$. marcescens em apenas duas, sendo que ambas não induziram mais resistência na cultivar resistente. Capone et al. (2011) avaliando o comportamento de quinze cultivares de cana-de-açúcar, encontraram divergências nos resultados para parâmetros quantitativos e qualitativos, portanto pode-se observar que as diferentes estirpes apresentam comportamentos diferenciados e as divergências nos resultados poderiam ser atribuídas ao genótipo da cultura, assim como nos resultados obtidos por Lopes et al. (2008) e Liu et al. (1995).

Olivares (1997) relatou que ocorrem diferentes níveis de interação entre bactérias e espécies de plantas ou ainda uma afinidade entre estirpes e cultivares. Esse comportamento pode também ter ocorrido no presente trabalho, entre o genótipo SP77-5181 e A. brasilense AbV5, já que não há nenhum relato que relacione o efeito dos genótipos à influência de bactérias endofíticas. Porém, ao contrário do observado, Silva et al. (2004) 
utilizando $A$. brasilense na reação de resistência de sementes de trigo e cevada à Bipolaris sorokiniana concluíram que em plantas tratadas com $A$. brasilense houve promoção do desenvolvimento, demonstrando que a bactéria interferiu no metabolismo da planta e atuou como elicitor de resistência. Contudo, esse resultado foi obtido em condições controladas. É sabido que fatores edáficos são fundamentais para qualquer processo biológico (Xavier, 2006).

Segundo Döbereiner e Pedrosa (1987), as condições ideais de $\mathrm{pH}$ para o crescimento de Azospirillum brasilense está entre 6,0 e 7,8 e para $H$. seropedicae o $\mathrm{pH}$ ideal para seu crescimento é variável entre 5,3 a $8,0 . \mathrm{O} \mathrm{pH}$ encontrado nas plantas para todos os tratamentos ficou com valor médio de 5,5. Esse fato pode estar associado com os resultados obtidos neste trabalho, onde o tratamento Azospirillum brasilense AbV5 + Leifsonia xyli subsp. xyli não apresentou diferenças positivas para as variáveis avaliadas.

\section{CONCLUSÕES}

A bactéria Herbaspirillumn seropedicae estirpe SmR1, mostrou-se como controlador biológico potencial à colonização de Leifsonia xyli subsp. $x y l i$, baseando-se em evidências indiretas, como o aumento da massa dos colmos e com tendência a maiores rendimentos de produção.

Aparentemente a bactéria Azospirillum brasiliense estirpe: AbV5 não causou efeitos detectáveis nos componentes de produção dos genótipos de canade-açúcar avaliados.

\section{RESUMO}

Este trabalho teve como objetivo avaliar o efeito de bactérias diazotróficas nos componentes de produção de cana-de-açúcar infectadas pelo raquitismo das soqueiras causado por Leifsonia xyli subsp. xyli. O ensaio foi conduzido na Estação Experimental de Paranavaí, PR, no ano de 2010. Os tratamentos foram constituídos de plantas do genótipo SP77-5181 inoculadas com: 1 . Azospirillum brasiliense estirpe AbV5 + Leifsonia xyli subsp. xyli; 2. Herbaspirillum seropedicae estirpe SmR1 + Leifsonia xyli subsp. xyli; 3. H. seropedicae estirpe HCC103 + Leifsonia xyli subsp. xyli; 4. Leifsonia xyli subsp. xyli; 5. Todas as bactérias (A. brasiliense estirpe AbV5 $+H$. seropedicae estirpes SmR1 e HCC103 + Leifsonia xyli subsp. xyli); 6. Testemunha sem inoculação. Foram realizadas as avaliações de: POL, toneladas de POL por hectare, teor de fibra, massa de 1 colmo, número de colmos por metro, estatura, diâmetro de colmos e toneladas de cana por hectare. A detecção do patógeno foi realizada pelo método Dot blot. O delineamento utilizado foi de blocos ao acaso, com três repetições. Verificou-se que $H$. seropedicae estirpe SmR1, mostrou-se como controlador biológico potencial à colonização de Leifsonia xyli subsp. xyli, baseando-se em evidências como aumento da massa dos colmos. Aparentemente a bactéria A. brasiliense estirpe: AbV5 não causou efeitos detectáveis nos componentes de produção avaliados.

Palavras-chave: Saccharum spp, Herbaspirillum seropediceae, Azospirillum brasiliense, bactérias endofíticas

\section{REFERÊNCIAS}

Capone, A.; Lui1, J. J.; Silva1, T. R.; Dias, M. A. R.; Melo, A. V. (2011), Avaliação do comportamento de quinze cultivares de cana-deaçucar na Região Sul do Tocantins. Journal of Biotechnology and Biodiversity, 3, 70-78.

Carneiro Jr., J. B.; Silveira, F. S.; De Ponte, E. (2006), Sanidade e vigor de mudas de cana-deaçúcar infectadas por Leifsonia xyli subsp. xyli e tratadas por termoterapia. Fitopatologia Brasileira, 31, 183, suplemento.

Carneiro Jr., J. B. Obtenção e análise de especificidade de antissoro (policlonal) contra Leifsonia xyli subsp. xyli, agente causal do RSD. Campo dos Goytacazes. Dissertação (mestrado em fitopatologia) - Centro de Ciências Tecnológicas, Universidade Estadual do Norte Fluminense, 2001.

Costa, J. M. T. e Ruschel, A. P. (1981), Seasonal variation in the microbial populations of sugarcane plants. In:VOSE, P. B., RUSCHEL, A. P.(Eds) CRC,109-118.

Damman, K. E. Jr. e Olliver, C. A. (1991), Distribution and incidence of ratoon stunting disease in Louisiana sugarcane. Plant disease,75, 568-571.

Döbereiner, J.; Baldani, V. L. D.; Reis, V. M. Endophytic occurrence of diazotrophic in nonleguminous crops. In: Azospirillum VI and related microorganisms (1995) (Ed: I. FENDRIK. et al.). Springer - Verlag, Berlin, Heidelberg, New York, 3-14.

Döbereiner, J. e Pedrosa, F. O. (1987) Nitrogenfixing bacteria in nonleguminous crop plants. Science Tech Publishers/Springer-Verlag. 
EMBRAPA, Centro Nacional de Pesquisa de Solos. Sistema brasileiro de classificação de solos (1999), Brasília, 412p.

Ferreira, D. F. Análises estatísticas por meio do Sisvar para Windows 4.0. (2000) In: Reunião anual da região brasileira da sociedade internacional de biometria, São Carlos: UFSCAR, 45, 255-258.

Harrison, N. A. e Davis, M. J. (1988), Colonization of vascular tissues by Clavibacter $x y l i$ subsp. xyli in stalks of sugarcane cultivars differing in susceptibility to roatoon stunting disease. Phytopathology, 78, 722-727.

INSTITUTO AGRONÔMICO DO PARANÁ. Cartas Climáticas do Estado do Paraná 1994 (1994), Londrina, 49 p. (IAPAR. Documento, 18).

Lee, T. S. G. (1988), Produção de mudas sadias de cana-de-açúcar através da técnica de cultura de tecidos. Álcool e Açúcar, Piracicaba, 45, 20-29.

Liu, L.; Kloepper, J. W.; Tuzun, S. (1995), Induction of systemic resistance in cucumber against fusarium wilt by plant growth-promoting rhizobacteria. Phytopathology, 85, 695-698.

Lopes, A. A. C.; Reis Junior, F. B. (2008), Efeito com a inoculação com Herbaspirillum seropedicae sobre a produtividade do milho nos períodos de safra e safrinha. Brasília. Anais. IX Simpósio Nacional Cerrado. II Simpósio Internacional Savanas Tropicais.

Okon, Y.; Vanderleyden, J. (1997), Rootassociated Azospirillum species can stimulate plants. American Society for Microbiology News, 63, 366-370.

Olivares, F. L.; Reis, V. M. e Façanha, A. R. (2000), The role of endophytic diazotrops in sugarcane rootmorphogenesis and development. In: Finan, T. M.; O'brian, M. R.; Layzell, D. B., Vessey, J. K. \& Newton. W., eds. Nitrogen fixation: Global perspectives. Oxon, CAB International, 476-477.
Olivares, F. L. Taxonomia, ecologia e mecanismos envolvidos na infecção e colonização de cana-deaçúcar (Saccharum sp. híbrido) por bactérias diazotróficas endofíticas do gênero Herbaspirillum. Tese (Doutorado) - Universidade Federal Rural do Rio de Janeiro, Seropédica. 1997.

Pedrosa, F. O.; Yates, M. G. (1984), Regulation of nitrogen fixation (nif) genes of Azospirillum brasilense by nifA and $n \operatorname{trC}(g \ln G)$ type genes. FEMS Microbiology Letters, 55: 95-101

Silva, H. S. A. Romeiro, R. S.; Macagnan, D.; Halfeld-Vieira, B. A.; Baracat-Pereira, M. C.; Mounteer, A. (2004), Rhizobacterial induction of systemic resistance in tomato plants: non-specific protection increase in enzyme activities. Biological Control, 29, 288-295.

Teakle, D. S.; Appleton, J. M.; Steindl, D. R. (1978), An anatomical basis for resistance of sugarcane to ratoon stunting disease. Physiol. Plant Pathology, 12, 83-91.

Tokeshi, H. Doenças da cana-de-açúcar (híbridos de Saccharum spp.) In: KIMATI, H. et al. Manual de Fitopatologia, 2: Doenças das Plantas Cultivadas. (1997), Editora Agronômica Ceres, São Paulo.

Xavier, R. P. Contribuição da fixação biológica de nitrogênio na produção sustentável da cultura de cana-de-acucar. Tese (Doutorado) Universidade Federal Rural do Rio de Janeiro, Seropédica-RJ, 2006.

Young, J. M.; Petrasovits, L. A.; Croft, B. J.; Gillings, M.; Brumbley, S. M. (2006), Genetic Uniformity of international isolates of Leifsonia xyli subsp. xily, causal agent of ratoon stunting disease of sugarcane. Australasian Plant Pathology, 35, 503-511. 